\title{
Prolonged activity of knee extensors and dorsal flexors is associated with adaptations in gait in diabetes and diabetic polyneuropathy.
}

Citation for published version (APA):

Savelberg, H. H. C. M., Ilgin, D., Angin, S., Willems, P. J. B., Schaper, N. C., \& Meijer, K. (2010).

Prolonged activity of knee extensors and dorsal flexors is associated with adaptations in gait in diabetes and diabetic polyneuropathy. Clinical Biomechanics, 25(5), 468-475.

https://doi.org/10.1016/j.clinbiomech.2010.02.005

Document status and date:

Published: 01/06/2010

DOI:

10.1016/j.clinbiomech.2010.02.005

Document Version:

Publisher's PDF, also known as Version of record

\section{Document license:}

Taverne

Please check the document version of this publication:

- A submitted manuscript is the version of the article upon submission and before peer-review. There can be important differences between the submitted version and the official published version of record.

People interested in the research are advised to contact the author for the final version of the publication, or visit the DOI to the publisher's website.

- The final author version and the galley proof are versions of the publication after peer review.

- The final published version features the final layout of the paper including the volume, issue and page numbers.

Link to publication

\footnotetext{
General rights rights.

- You may freely distribute the URL identifying the publication in the public portal. please follow below link for the End User Agreement:

www.umlib.nl/taverne-license

Take down policy

If you believe that this document breaches copyright please contact us at:

repository@maastrichtuniversity.nl

providing details and we will investigate your claim.
}

Copyright and moral rights for the publications made accessible in the public portal are retained by the authors and/or other copyright owners and it is a condition of accessing publications that users recognise and abide by the legal requirements associated with these

- Users may download and print one copy of any publication from the public portal for the purpose of private study or research.

- You may not further distribute the material or use it for any profit-making activity or commercial gain

If the publication is distributed under the terms of Article $25 \mathrm{fa}$ of the Dutch Copyright Act, indicated by the "Taverne" license above, 


\title{
Prolonged activity of knee extensors and dorsal flexors is associated with adaptations in gait in diabetes and diabetic polyneuropathy
}

\author{
Hans H.C.M. Savelberg a,*, Duygu Ilgin ${ }^{\mathrm{b}}$, Salih Angin ${ }^{\mathrm{b}}$, Paul J.B. Willems ${ }^{\mathrm{a}}$, Nicolaas C. Schaper ${ }^{\mathrm{c}}$, \\ Kenneth Meijer ${ }^{\text {a }}$ \\ a Department of Human Movement Sciences, Nutrition and Toxicology Research Institute, Maastricht, Faculty of Health, Medicine and Life Sciences, Maastricht University, \\ Maastricht, The Netherlands \\ ${ }^{\mathrm{b}}$ School of Physical Therapy and Rehabilitation, Dokuz Eylul University, Izmir, Turkey \\ ${ }^{\mathrm{c}}$ Department of Internal Medicine, Cardiovascular Research Institute Maastricht, Maastricht University Medical Centre, Maastricht, The Netherlands
}

\section{A R T I C L E I N F O}

\section{Article history:}

Received 17 June 2009

Accepted 9 February 2010

\section{Keywords:}

Gait analysis

Electromyography

Gait velocity

\begin{abstract}
A B S T R A C T
Background: People with diabetes or diabetic polyneuropathy often experience limitations in mobility and gait. These limitations are believed to be related to disturbed muscle function and sensory information. In previous studies on diabetic gait, results were confounded by a lower, preferred walking speed in people with diabetes or diabetic polyneuropathy. This study aimed to identify gait-velocity independent effects of diabetes and diabetic polyneuropathy on lower extremity kinematics and muscle activation patterns.

Methods: Eight people with diabetic polyneuropathy, 10 diabetic controls without polyneuropathy and ten healthy, age-matched controls walked at their preferred velocity and a standard velocity of $1.4 \mathrm{~ms}^{-1}$. Muscle activation patterns of gluteus maximus, biceps femoris, rectus femoris, vastus medialis, gastrocnemius medialis, soleus, and tibialis anterior, and spatiotemporal and joint angles characteristics were analysed.

Findings: Independent of walking speed, muscle activation differed between groups. In diabetic polyneuropathy participants activation of ankle-joint dorsal flexors was prolonged by $5-10 \%$ of the stride cycle. Activity of monoarticular knee-joint extensors lasted about $10 \%$ longer in both diabetic groups compared to healthy elderly. Initiation of muscle activity did not differ between groups. If gait velocity was controlled, spatiotemporal characteristics were similar between groups.

Interpretation: The study showed that independent of the preferred lower gait velocity, people with diabetes or diabetic polyneuropathy adjust the timing of muscle activity. Contrarily, the concurrent changes in spatiotemporal characteristics occurred to be the result of changed velocity only. The delayed cessation of muscle activity suggested a reduced rate of force development underlying the adjusted timing of muscle activation.
\end{abstract}

(c) 2010 Elsevier Ltd. All rights reserved.

\section{Introduction}

Diabetic gait has been characterized by various adaptations compared to normal gait. Reduced gait velocity, step length, step frequency, redistributed joint moments, increased plantar pressures, postural instability and increased risk and fear of falling have been reported for patients with diabetes or diabetic polyneuropathy (Abboud et al., 2000; Caselli et al., 2002; Cavanagh et al., 1992, 1993; Courtemanche et al., 1996; Giacomozzi et al., 2002; Katoulis et al., 1997; Kwon et al., 2003; Lavery et al., 2003; Menz

\footnotetext{
* Corresponding author. Address: Department of Human Movement Science, Nutrition and Toxicology Research Institute, Maastricht, Faculty of Health, Medicine and Life Sciences, Maastricht University, PO Box 616, NL-6200MD Maastricht, The Netherlands.

E-mail address: hans.savelberg@bw.unimaas.nl (H.H.C.M. Savelberg).
}

et al., 2004; Mueller et al., 1994; Pataky et al., 2005; Petrofsky et al., 2005; Richardson et al., 1992; Savelberg et al., 2009; Yavuzer et al., 2006). In a recent review by Allet et al. (2008) a comprehensive overview of gait adaptations in diabetes has been presented. These adaptations limit the mobility of diabetic patients, which likely contributes to increased dependence and reduced quality of life (Gregg et al., 2000).

It has been suggested that adaptations in muscle function underlie these changes in gait pattern (Abboud et al., 2000; Savelberg et al., 2009; Yavuzer et al., 2006). ElectroMyoGraphy (EMG) has been used in kinesiology to assess electric activity of muscle. In comparing individuals or groups of individuals especially the timing of muscle activation can provide useful information. A delayed initiation of EMG-activity might be interpreted as a disturbance of nerve function or sensory input to the muscle, or even 
poor control to compensate for sensory deficits. Prolonged activity and postponed cessation can be seen as compensation for reduced capacity of muscle to generate force. With respect to diabetic gait several studies have analysed muscle activation, results of these studies were inconclusive. Abboud et al. (2000) found in patients with diabetes a reduced and delayed activation peak of tibialis anterior. Kwon et al. (2003) reported in people with diabetic polyneuropathy prolonged activation in soleus, vastus medialis, medial hamstrings and tibialis anterior; moreover they found delayed onset of activity for the triceps surae group. Sacco and Amadio (2003) found in people with diabetic polyneuropathy a delayed activation peak of vastus lateralis and tibialis anterior. Akashi et al. (2008) reported delayed peaks in EMG-activity of vastus lateralis and gastrocnemius lateralis, but only in a group of people with diabetic polyneuropathy that had a foot sole ulceration. People with diabetic polyneuropathy that had not developed an ulcer did not show a delay in the activation peak. Although all of these studies provided evidence that muscle activation is affected in diabetic gait, inconsistency exists about the direction of adaptations. It remains unclear whether muscle activation in patients with diabetes is delayed or prolonged. In addition it cannot be concluded that these adaptations are caused by the diabetic condition. In these studies diabetic participants walked slower than healthy subjects. As gait velocity affects gait parameters (e.g. (Hortobágyi et al., 2009; Lelas et al., 2003; Stoquart et al., 2008)), it cannot be excluded that the reported adaptations result from the reduced walking speed, and not directly from the diabetic condition itself.

The aim of the present study was to independently evaluate the influence of gait velocity and diabetes and diabetic polyneuropathy on muscle activation patterns and lower limb kinematics during gait. To this end, subjects with diabetic polyneuropathy (DPN), diabetic controls without neuropathy (DC) and age-matched healthy controls (HC) walked at their own preferred gait velocity and at a standard, imposed velocity that was similar for all participants.

\section{Methods}

\subsection{Subjects}

Twenty eight subjects were recruited to take part in this study; they were divided in three groups: subjects with diabetic polyneuropathy (DPN, $n=8$ ), diabetic controls without diabetic polyneuropathy (DC, $n=10$ ) and healthy age-matched controls (HC, $n=10$; Table 1 ).

The two groups of diabetic subjects were recruited from the outpatient clinic of the Maastricht University Medical Centre. The healthy, elderly control subjects were recruited from an existing database at the Department of Human Movement Science of Maastricht University. The study was approved by the Local Ethics Com-

Table 1

Subject characteristics of the groups.

\begin{tabular}{lllll}
\hline & DPN & DC & HC & $\begin{array}{l}P \text { - } \\
\text { value }\end{array}$ \\
\hline Sex (female:male) & $1: 7$ & $3: 7$ & $2: 8$ & NA \\
Age (years) & $68.9(6.3)$ & $60.5(6.9)$ & $72.4(6.0)$ & $\mathbf{0 . 0 0 3}$ \\
Body mass (kg) & $84.1(10.9)$ & $81.3(13.3)$ & $71.5(10.0)$ & 0.062 \\
Body length (m) & $1.73(0.06)$ & $1.67(0.10)$ & $1.70(0.07)$ & 0.332 \\
BMI (kg/m ${ }^{2}$ ) & $28.0(3.2)$ & $29.2(3.7)$ & $24.7(2.9)$ & $\mathbf{0 . 0 0 8}$ \\
Right leg length (m) & $0.82(0.04)$ & $0.77(0.08)$ & $0.78(0.06)$ & 0.311 \\
Vibration perception & $38.1(8.4)$ & $17.9(6.7)$ & $21.8(8.4)$ & $\mathbf{0 . 0 0 2}$ \\
$\quad$ threshold (V) & & & & \\
HbA1c (\%) & $8.1(0.6)$ & $8.8(2.0)$ & & 0.360 \\
Duration of diabetes (years) $^{\mathrm{a}}$ & $19.0(13.6)$ & $10.2(5.4)$ & & 0.314 \\
\hline
\end{tabular}

Data are presented as means (standard deviations).

${ }^{a}$ DC: $n=5$, DPN $n=6$. mittee of Maastricht University Medical Centre. Prior to the start of the trials all subjects had been informed about the tests and they signed an informed consent form.

Polyneuropathy was diagnosed based on a standardized clinical, neurological examination which included sensory testing, tendon reflexes, and muscle strength in the lower extremities (Valk et al., 1992). To be included metabolic control of the diabetic participants had to be well regulated. Further inclusion criteria were: able to walk independently without pain and without an assistive device and blood glucose concentration between 5 and $16 \mathrm{mmol}^{-1}$ during the test trials. Exclusion criteria were foot deformities (charcot deformation or amputation of parts of the foot or toes), active ulcerations of the plantar foot surface or previous amputations of the foot or parts of it, severely restricted mobility of lower extremity joints (less than 10 degrees of dorsal flexion or less than 30 degrees of plantar flexion), existence of any diagnosed cardiopulmonary and/or neuromusculoskeletal disease within last year other than diabetic polyneuropathy and bodymass index $(\mathrm{BMI})>35$.

\subsection{Study protocol}

Subjects wore shorts and a T-shirt, and walked barefoot. Age, sex, weight, standing height, length of the right leg, and peripheral sensation of the subjects were assessed. Peripheral sensation was quantified by measuring the vibration perception threshold (VPT) under the big toe, using a biothesiometer. VPT was defined as the lowest amplitude of vibration that a subject could perceive. The overall score of VPT was calculated from the mean of 10 trials. In case subjects were not able to detect any vibration, a score of '>50' was assigned to the VPT (Van Deursen et al., 2001). To estimate whether subjects could safely participate in the tests, blood glucose concentration was measured before each measurement. After the measurements it was checked again to control for too low levels.

To assess joint kinematics retro-reflective markers were placed on anatomical landmarks on the right side of the subject: on the lateral border of the fifth metatarsal head, tuber calcanei, lateral malleolus, lateral femur condyle, and greater trochanter. Body positions in the sagital plane were recorded using a 2-D digital optical recording system, which consisted of a $25 \mathrm{~Hz}$ interlaced digital video camera (50 frames/s) (MX5, Adimec, Holland) with a $12.5 \mathrm{~mm}$ lens (Ernitec). Video images were stored on a computer via an 8-bit frame-grabber (DMA magic, Matrox, UK, $512 \times 512$ pixels), programmed with DMA magic (DIFA measuring systems, Breda, Holland). These measurements provided information about gait velocity, positions of body segments, range of motion in the hip, knee and ankle joints.

Using bipolar surfaces sensors (circular $\mathrm{Ag} / \mathrm{AgCl}$ electrodes, $10 \mathrm{~mm}$ diameter, interelectrode distance $20 \mathrm{~mm}$, Meditrace) the activity of major muscle groups was recorded at $1000 \mathrm{~Hz}$. Amplified signals (K-lab, Amsterdam, the Netherlands) were A/D (12 bits) converted and all data was stored on a PC with data-acquisition equipment. EMG-recording and the digital camera were synchronised. In agreement with the SENIAM recommendation (Hermens et al., 2000), the skin was prepared and the locations of EMG-electrodes were chosen. The activity of the following muscles was monitored: $m$. gastrocnemius medialis (GaM), $m$. soleus (S), $m$. tibialis anterior (TA), $m$. vastus medialis (VM), m. rectus femoris (RF), m. biceps femoris (BF), and m. gluteus maximus (GMax). A reference electrode was placed on the right wrist.

Subjects walked along a $12 \mathrm{~m}$ long walkway with an embedded force platform (Kistler Type 9281A). They walked both at their selfselected pace, and at a standard, imposed velocity $\left(1.4 \mathrm{~ms}^{-1}\right)$ that was similar for all participants. Prior to data collection of each condition the subjects were allowed to practice trials to get familiar 
with the equipment. For each velocity condition five trials were recorded. Recording started by pressing a synchronization trigger right after the subject started walking. Duration of data-acquisition was five seconds. A trial was considered successful if the participant landed on the force platform with the right foot, and for the imposed velocity conditions, if the velocity ranged between 1.3 and $1.5 \mathrm{~ms}^{-1}$.

\subsection{Data analysis}

Gait velocity was defined as the average forward velocity of the trochanter major marker. Stride duration was calculated as the time between subsequent onsets of GMax activity. Stance phase duration was defined as the time of contact of the foot with the force platform. Relative duration of stance phase was calculated by the ratio of stance duration to stride duration.

Cartesian co-ordinates of the reflective markers derived from the video records were used to calculate hip, knee, and ankle joint angles. The angle on the anterior side between the vertical and the line connecting the greater trochanter and the lateral femur condyle markers defined the hip joint angle. The maximal hip joint angle defined maximal hip joint extension of the hip joint, the minimal hip joint angle represented maximal flexion. The knee joint angle was defined as the angle on the posterior side between the line that connected the greater trochanter and the lateral femur condyle markers and the line that connected the lateral femur condyle and the lateral malleolus markers. The maximal knee joint angle resembled maximal knee joint extension, the minimal angle maximal knee joint flexion. For the ankle joint, the angle on the anterior side between the line that connected the lateral femur condyle and the lateral malleolus marker and the line connecting the tuber calcanei and the lateral border of the fifth metatarsal head defined the ankle joint angle. Maximal values of this variable presented maximal plantar flexion of the ankle joint, minimal values maximal dorsiflexion.

The raw EMG data were rectified and filtered using a 4th order Butterworth filter, with a cut off frequency of $10 \mathrm{~Hz}$. Muscles were considered active if the EMG value was above $20 \%$ of the maximal, processed EMG-signal (Hug and Dorel, 2009). To characterize muscle activity the ratio of duration of muscle activity relative to the stride duration, and the instants of beginning and ending of muscle activity as percentage of the stride duration were determined. At each joint, as a measure of coactivity, the percentage of the stride duration that antagonistic muscles were simultaneously active was calculated. To assess the relative effort of a muscle at the test velocity, the maximal, processed EMG amplitude at the imposed velocity was divided by the maximal, processed EMG amplitude at the individually preferred velocity. This ratio will indicate how much extra activation will be needed in the imposed velocity condition, compared to the preferred velocity.

All EMG and joint angle variables were determined for the stride that started with the heel strike on the force platform.

\subsection{Statistical analysis}

For each subject, variables were averaged over the measured trials, with a minimum of three trials. In the DPN group for one subject the data-acquisition during the imposed velocity failed, in the DC group this occurred for one subject in the preferred velocity condition. It was checked whether data were normally distributed and whether variances were similar in different groups. This occurred to be the case. A two-way repeated measures analysis of variance, with gait velocity as a within-subject factor and the three groups of participants as a between-subjects factor was used to test differences in temporal stride characteristics, joint kinematics and EMG variables. A one-way repeated-measures analysis of variance was applied to test differences in subject characteristics and in muscle effort at the test velocity between the subject groups. A level of significance of $P<0.05$ was chosen. Post-hoc tests (LSD) were used to locate bilateral differences between groups. All statistical tests were performed in SPSS version 15.0 for Windows.

\section{Results}

\subsection{Subject characteristics}

On the average DC participants were 10 years younger than DPN and HC subject $(P=0.003$, Table 1$)$. Healthy controls had a significantly smaller BMI than the other participants $(P=0.008)$. Body mass, body height and right leg length did not differ between the groups. Sensibility of the plantar surface turned out to be significantly more affected in the DPN group compared to the DC and the HC group $(P=0.002)$. Range of motion of the ankle joint did not differ between the groups (DPN: $57.5 \pm 8.5$ degrees; DC: $64.0 \pm 8.1$ degrees; HC: $60.5 \pm 9.0$ degrees; $P=0.287$ ).

\subsection{Spatiotemporal gait characteristics}

Although the HC group tended to walk faster than both diabetic groups, this difference was statistically not significant (Table 2). All subjects walked slower at the preferred gait velocity than at imposed gait velocity $(P<0.001)$. In the imposed gait velocity the stride duration $(P<0.001)$ was smaller and stride length $(P=0.005)$ was larger. The relative stance duration was not af-

Table 2

Spatiotemporal gait characteristics of the groups.

\begin{tabular}{|c|c|c|c|c|c|c|}
\hline & \multirow[t]{2}{*}{ DPN } & \multirow[t]{2}{*}{ DC } & \multirow[t]{2}{*}{$\mathrm{HC}$} & \multicolumn{3}{|c|}{$P$-values } \\
\hline & & & & Group & Velocity & Group $*$ velocity \\
\hline \multicolumn{7}{|c|}{ Gait velocity $\left(\mathrm{ms}^{-1}\right)$} \\
\hline Preferred & $1.02(0.13)$ & $1.06(0.13)$ & $1.18(0.22)$ & 0.374 & $<0.001$ & 0.233 \\
\hline Imposed & $1.37(0.15)$ & $1.41(0.18)$ & $1.41(0.17)$ & & & \\
\hline \multicolumn{7}{|c|}{ Stride duration (ms) } \\
\hline Preferred & $1152(176)$ & $1126(148)$ & $1117(108)$ & 0.843 & $<0.001$ & 0.356 \\
\hline Imposed & $898(93)$ & $968(92)$ & $941(73)$ & & & \\
\hline \multicolumn{7}{|c|}{ Stride length $(m)$} \\
\hline Preferred & $1.15(0.15)$ & $1.22(0.13)$ & $1.28(0.15)$ & 0.402 & 0.005 & 0.410 \\
\hline Imposed & $1.26(0.17)$ & $1.36(0.22)$ & $1.33(0.20)$ & & & \\
\hline \multicolumn{7}{|c|}{ Stance phase duration (ms) } \\
\hline Preferred & $640(58)$ & $622(41)$ & $611(36)$ & 0.433 & 0.884 & 0.632 \\
\hline Imposed & $650(79)$ & $608(46)$ & $622(80)$ & & & \\
\hline
\end{tabular}

Data are presented as means (standard deviations). 
Table 3

Ankle, knee and hip joint angle characteristics of the stance phase.

\begin{tabular}{|c|c|c|c|c|c|c|}
\hline & \multirow[t]{2}{*}{ DPN } & \multirow[t]{2}{*}{ DC } & \multirow[t]{2}{*}{$\mathrm{HC}$} & \multicolumn{3}{|c|}{$P$-values } \\
\hline & & & & Group & Velocity & Group $*$ velocity \\
\hline $\begin{array}{l}\text { Ankle joint } \\
\text { Maximal dorsiflexion ang }\end{array}$ & & & & & & \\
\hline $\begin{array}{l}\text { Preferred gait velocity } \\
\text { Imposed gait velocity }\end{array}$ & $\begin{array}{l}123.8(6.4) \\
124.2(5.8)\end{array}$ & $\begin{array}{l}121.1(9.5) \\
120.2(10.6)\end{array}$ & $\begin{array}{l}120.8(5.0) \\
120.6(3.7)\end{array}$ & 0.576 & 0.723 & 0.627 \\
\hline $\begin{array}{l}\text { Maximal plantarflexion a } \\
\text { Preferred gait velocity } \\
\text { Imposed gait velocity }\end{array}$ & $\begin{array}{l}105.5(4.2) \\
108.2(5.1)\end{array}$ & $\begin{array}{l}100.6(9.3) \\
103.8(5.1)\end{array}$ & $\begin{array}{l}103.3(4.8) \\
103.4(5.0)\end{array}$ & 0.369 & 0.001 & 0.040 \\
\hline $\begin{array}{l}\text { Ankle joint range of moti } \\
\text { Preferred gait velocity } \\
\text { Imposed gait velocity }\end{array}$ & $\begin{array}{l}18.3(5.6) \\
16.0(3.5)\end{array}$ & $\begin{array}{l}20.5(4.0) \\
16.3(2.3)\end{array}$ & $\begin{array}{l}17.5(3.1) \\
17.3(4.2)\end{array}$ & 0.703 & 0.011 & 0.139 \\
\hline $\begin{array}{l}\text { Knee joint } \\
\text { Maximal knee joint flexio } \\
\text { Preferred gait velocity } \\
\text { Imposed gait velocity }\end{array}$ & $\begin{array}{l}\text { egrees) } \\
159.0(4.5) \\
155.0(4.8)\end{array}$ & $\begin{array}{l}155.8(4.1) \\
151.2(4.7)\end{array}$ & $\begin{array}{l}156.6(5.6) \\
155.5(7.2)\end{array}$ & 0.375 & $<0.001$ & 0.025 \\
\hline $\begin{array}{l}\text { Maximal knee joint exten } \\
\text { Preferred gait velocity } \\
\text { Imposed gait velocity }\end{array}$ & $\begin{array}{l}\text { (degrees) } \\
168.3(5.1) \\
168.2(5.4)\end{array}$ & $\begin{array}{l}165.7(5.8) \\
165.0(4.9)\end{array}$ & $\begin{array}{l}171.0(7.3) \\
172.4(5.9)\end{array}$ & 0.076 & 0.702 & 0.212 \\
\hline $\begin{array}{l}\text { Knee joint range of motic } \\
\text { Preferred gait velocity } \\
\text { Imposed gait velocity }\end{array}$ & $\begin{array}{l}9.2(4.5) \\
13.2(4.8)\end{array}$ & $\begin{array}{l}9.9(3.4) \\
13.8(3.5)\end{array}$ & $\begin{array}{l}14.3(5.1) \\
16.9(4.3)\end{array}$ & 0.048 & $<0.001$ & 0.676 \\
\hline $\begin{array}{l}\text { Hip joint } \\
\text { Maximal hip joint flexion } \\
\text { Preferred gait velocity } \\
\text { Imposed gait velocity }\end{array}$ & $\begin{array}{l}\text { rrees) } \\
157.7(1.4) \\
155.8(2.7)\end{array}$ & $\begin{array}{l}155.2(3.5) \\
152.7(4.2)\end{array}$ & $\begin{array}{l}157.2(4.3) \\
156.4(5.2)\end{array}$ & 0.241 & $<0.001$ & 0.231 \\
\hline $\begin{array}{l}\text { Maximal hip joint extens } \\
\text { Preferred gait velocity } \\
\text { Imposed gait velocity }\end{array}$ & $\begin{array}{l}\text { degrees) } \\
192.9(4.9) \\
194.9(5.7)\end{array}$ & $\begin{array}{l}193.1(5.2) \\
194.4(5.2)\end{array}$ & $\begin{array}{l}197.6(4.7) \\
199.1(3.9)\end{array}$ & 0.079 & 0.009 & 0.861 \\
\hline $\begin{array}{l}\text { Hip joint range of motion } \\
\text { Preferred gait velocity } \\
\text { Imposed gait velocity }\end{array}$ & $\begin{array}{l}35.1(5.0) \\
39.1(6.9)\end{array}$ & $\begin{array}{l}38.0(4.1) \\
41.7(4.7)\end{array}$ & $\begin{array}{l}40.5(4.9) \\
42.7(4.8)\end{array}$ & 0.159 & 0.001 & 0.677 \\
\hline
\end{tabular}

Data are presented as means (standard deviations).

fected by gait velocity. None of the temporal characteristics differed between groups.

\subsection{Joint angles}

In general joint angle characteristics were affected by gait velocity, and differed only in a few cases between groups (Table 3 ).

The hip joint was in the imposed velocity condition more flexed at heel strike $(P<0.001)$ and more extended at toe off $(P=0.009)$ than in the preferred velocity condition. The hip joint angle pattern did not differ between the groups. Compared to the HC group the knee joint flexion angle was in both diabetic groups more flexed in the imposed velocity than in the preferred velocity condition (group $*$ velocity interaction $P=0.025$ ).

The range of knee joint motion during the stance phase was smaller in the preferred than in the imposed velocity condition $(P<0.001)$. In addition the range was smaller in both diabetic groups than in the HC group $(P=0.048)$.

At the instant, shortly before toe-off the ankle joint angle was more plantar flexed in both diabetic groups smaller in the preferred gait velocity condition than in the imposed velocity condition (group $*$ velocity interaction $P=0.040$ ). In the healthy subjects the ankle joint was not affected by gait velocity.

\subsection{Timing of muscle activation}

In TA and VM a difference in the timing of muscle activity between the groups occurred. In DPN participants TA remained sig- nificantly longer active than in both other groups. In DPN participants TA was switched off at $22 \%$ of the gait cycle, in the other participants TA activity ceased at approximately $15 \%$ of the cycle (Table 4 (supplementary data available on internet); Fig. 1). In both diabetic groups VM activity lasted significantly longer than in the HC group; in the diabetic groups VM was switched off at about $50 \%$ of the gait cycle in the HC this occurred at $39 \%$ of the cycle. The activation of the RF was extended in the DPN group in the imposed velocity condition (group $*$ velocity interaction $P=0.014)$.

Gait velocity affected significantly the cessation of activity of GMax, in the imposed velocity condition the activation was switched of about $5 \%$ earlier. Also in the imposed velocity condition TA became active about $4 \%$ earlier. These differences in timing of the activation resulted in TA and GMax in differences in the duration of activity. Under the imposed velocity condition the total relative duration of GMax was about $3 \%$ of the gait cycle duration shorter. The duration of TA activity was increased in the imposed velocity; moreover it lasted longer in the DPN group than in both other groups. In the RF a $9 \%$ increase of duration was found for DPN participants in the imposed velocity condition.

\subsection{Amplitude}

For all groups the relative effort in the imposed gait velocity condition was the same as in the preferred gait velocity condition (data not shown). 

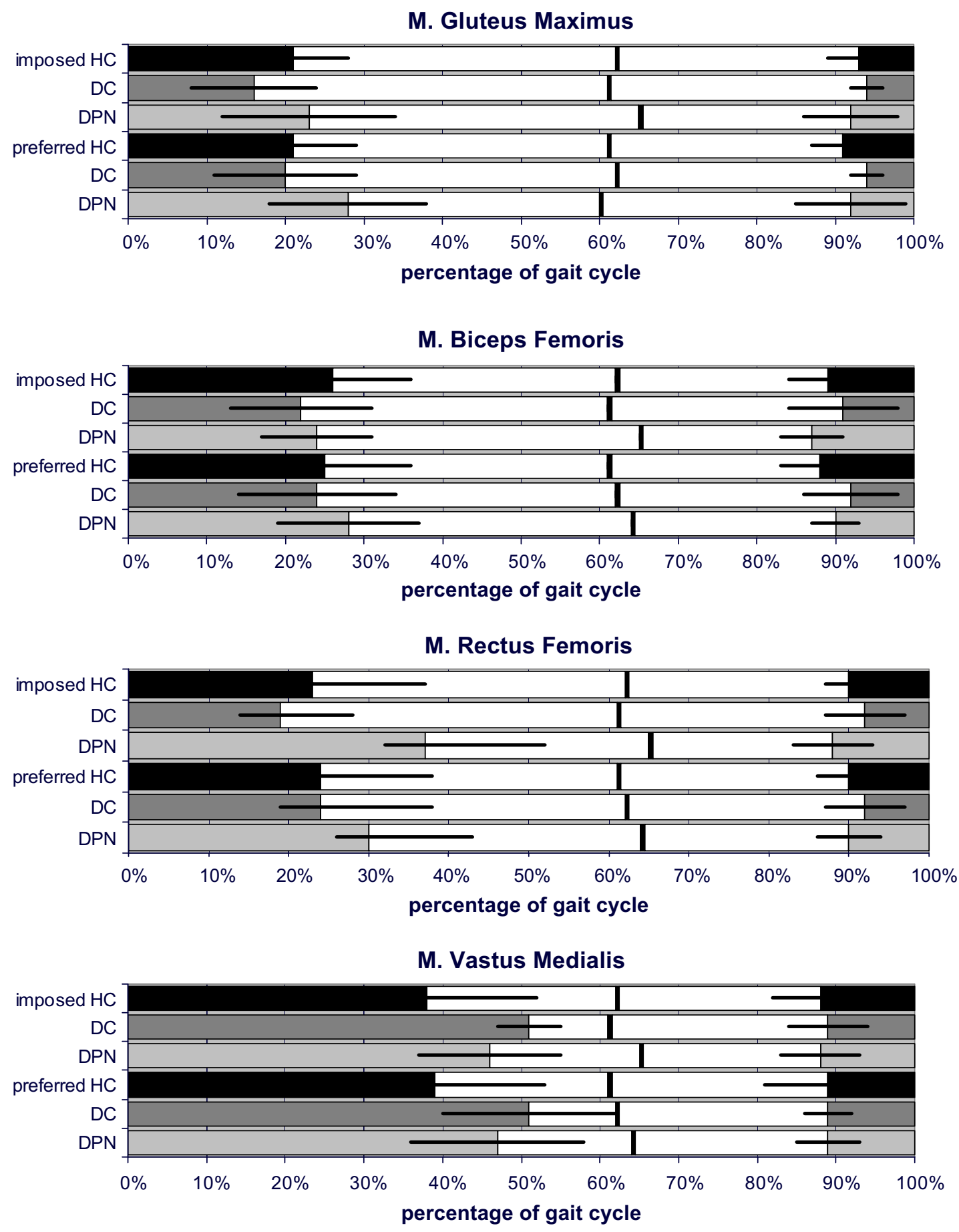

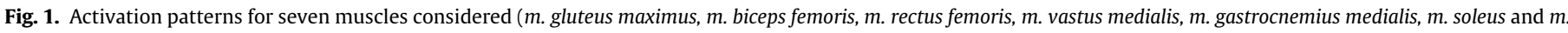

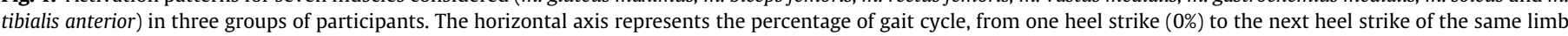

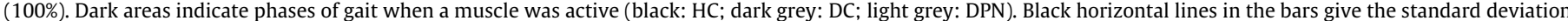

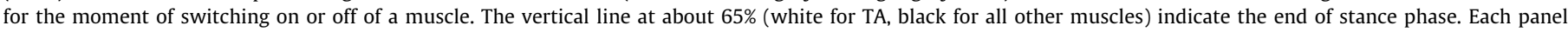
contains data for the imposed gait velocity (upper three bars) and for the preferred gait velocity (lower three bars).

\section{Discussion}

In this study we aimed to separate the effects of walking velocity and diabetic conditions on muscle activation, joint kinematics and spatiotemporal characteristics of gait. We found that spatiotemporal characteristics did not differ between healthy controls, people with diabetic polyneuropathy and participants with diabetes, if participants were asked to walk at the same gait velocity.
Only if gait velocity was not experimentally controlled, stride duration and stride length changed; this held for all groups (Table 2). Joint kinematics turned out to differ only minimally between the groups, but was considerably affected by gait velocity (Table 3 ). Timing of muscle activation was susceptible to both diabetic condition of participants and walking velocity (Table 4 (supplementary data available on internet). In both diabetic groups cessation of activities of ankle-joint dorsal flexors (TA) and of mono articular 


\section{Gastrocnemius Medialis}

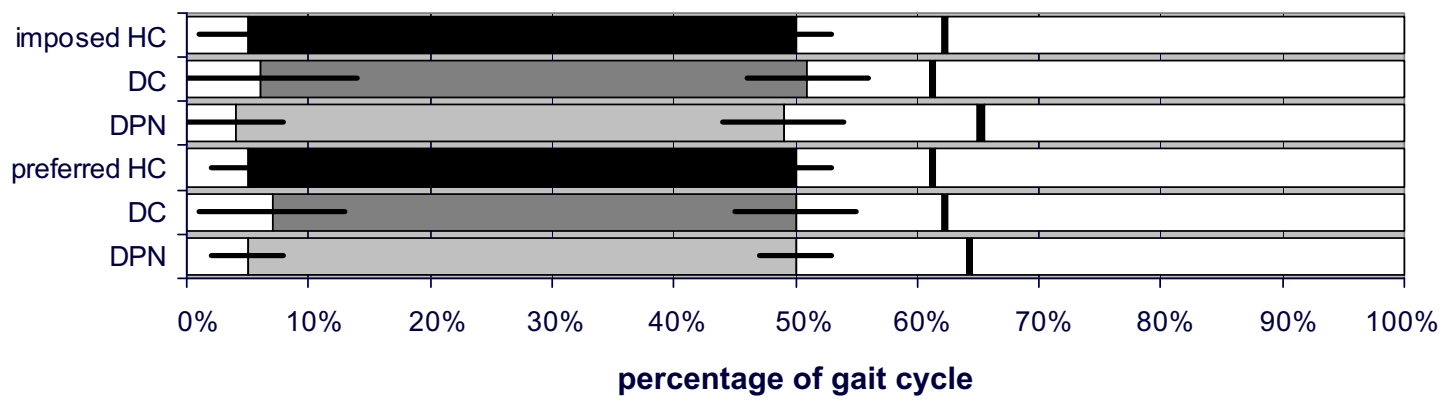

M. Soleus

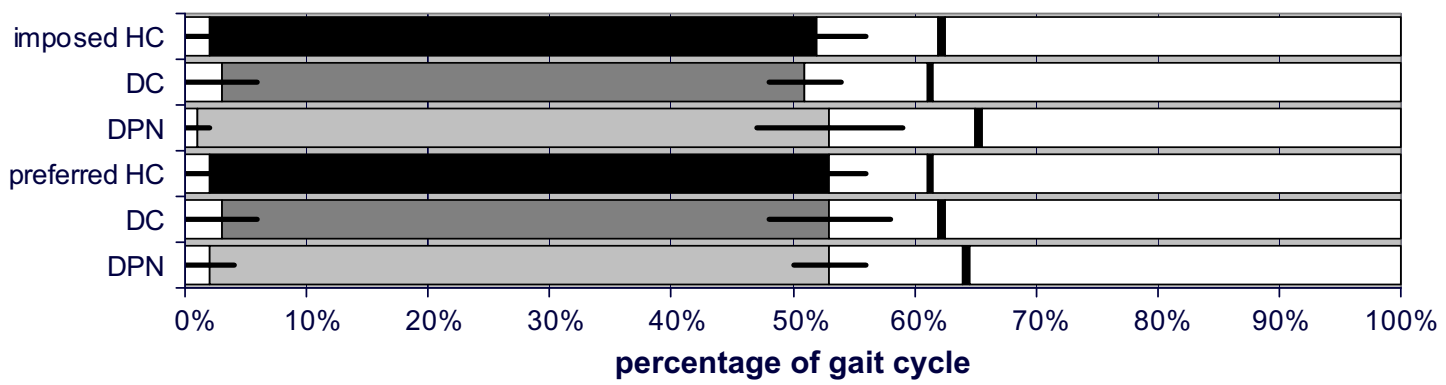

M. Tibialis Anterior

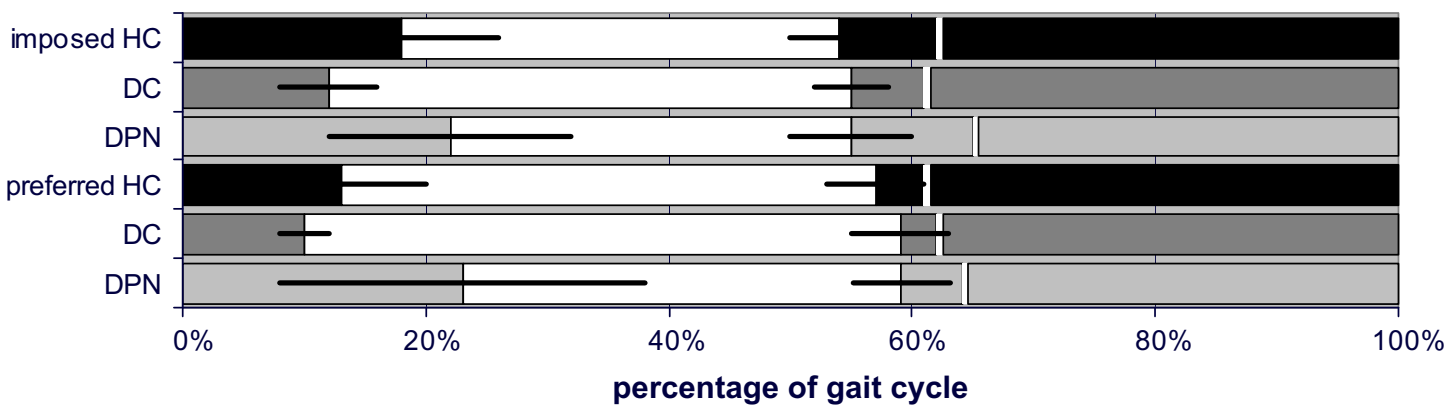

Fig. 1 (continued)

knee-joint extensors were significantly delayed compared to healthy controls; this was found for both gait velocities. Increasing gait velocity caused different adaptations of timing of muscle activation.

This suggests that spatiotemporal changes that have been reported in previous diabetic gait studies that did not control gait should be attributed to differences in gait velocity that occur with diabetes and diabetic polyneuropathy. Results on joint kinematic and muscle activation that have been presented in previous studies can be expected to be the mixed effect of diabetic status and reduced walking speed.

\subsection{Limitation of the present study}

In this study subjects were not optimally matched for BMI and age. Theoretically, these factors might affect muscle activation and gait kinematics. If people with and without diabetes type 2 have to be included, it is very hard, almost impossible, to match participants for BMI. On average diabetic participants with the same body length have larger body mass than people without diabetes. As body length and leg length are known to affect gait velocity (Hof, 1996), we have chosen to match participants in different groups for body length, and take a difference in BMI for granted. This im- plies that it cannot be confirmed that group differences represent different diabetic status; group differences might as well be related to differences in relative body mass.

Subjects in the diabetes control group were on the average about 10 years younger than the participants in both other groups. Although effects of age differences between subgroups of seniors will theoretically exist, we expect them to be small, and to have only a minor affect on the outcome of the study. Hortobágyi et al. (2009) compared muscle activation patterns between young and older subjects. They found differences in timing of EMG-activity between these groups comparable to the differences we found between diabetic patients and healthy seniors. This supports our idea that differences between subgroups of seniors will not be large enough to affect the results of our study.

Although the number of subjects resembles that of similar studies, it might have affected the statistical power, resulting in conservative conclusions with respect to differences between groups and conditions. Some differences that exist between groups or velocity conditions might erroneously not have been noticed. That might interfere with the conclusion that group differences do not underlie differences in kinematics. The difference in gait velocity between groups might have failed to be significant due to limited statistical power. The $P$-values reported for the influences of 
groups and conditions are typically either below 0.05 or considerably above 0.1 . Especially, the latter indicates that the change of non-detected differences is low. For the group effect on maximal knee joint extension angle and maximal hip joint extension angle $P$-values between 0.05 and 0.10 were found. For these variables the low number of subjects might have resulted in a too conservative approach. Therefore, in spite of the minimal number of significant variables, it cannot be concluded that group differences do not underlie differences in joint angle patterns.

\subsection{Prolonged activity}

Striking in the adapted activation patterns was that only dorsal flexors of the ankle joint and extensors of the knee joint were found to be affected by diabetes or diabetic polyneuropathy, and moreover that adaptations appeared at the end of the active phase. The dorsal flexors and knee-joint extensors are active during the first half of the stance phase and play a role in braking the forward velocity and controlling the forward displacement of the centre of mass and the centre of pressure under the foot. In a previous publication (Savelberg et al., 2009) we suggested that reduced capacity to control the forward displacement of the centre of pressure resulted in a redistribution of plantar pressures under the foot (Caselli et al., 2002; Pataky et al., 2005). The extended activity of these muscles - reported in the present study - can be interpreted as an increased effort to control the forward displacement. This would be in line with the idea that these muscles have difficulties to generate enough braking impulse during the first part of the stance phase. The latter agrees with data by Meier et al. (2001); they reported disturbed gait termination in people with diabetic polyneuropathy.

The prolonged muscle activity is in agreement with the results of Kwon et al. (2003). In addition, they reported prolonged activity in hamstrings and soleus. Moreover they reported premature activity of some muscles in people with diabetes. In their study subjects with diabetes walked considerably slower than control subjects, moreover the body-mass index of their subjects was higher. These methodological variations may underlie the different findings. This also suggests that the adaptations reported by Kwon et al. (2003) represent a mixed effect of gait velocity and diabetes. Sacco and Amadio (2003) compared muscle activation in people with diabetic polyneuropathy and healthy controls, although they did not evaluate onset and offset of activation, the figures they presented suggest a prolonged activity of the dorsal flexors in the diabetic polyneuropathy group. Abboud et al. (2000) and Akashi et al. (2008) reported delayed peak activity in subjects with varying degrees of diabetes.

The adapted timing of muscle activation might originate from neuronal or muscular dysfunction. It can be speculated that as a consequence of disturbed sensory input (Valk et al., 1992) muscle excitation reaches its optimal level later and that a longer activation is required to generate the desired muscle impulse. Alternatively, it might be hypothesized that prolonged activation is required due to a disturbed rate of force generating capacity in muscle. Gutierrez et al. (2001) concluded that people with diabetic polyneuropathy have a decrease in rapidly available ankle joint strength. Similar results were reported by Nielsen et al. (2004); they found in people with type 1 diabetes increased rise time of $m$. soleus contraction. Cameron et al. (1990) studied contractile properties of muscles in streptozocin-induced diabetes in rats, they suggested that disturbance of the $\mathrm{Ca}^{2+}$ handling underlies slowing of twitch times. In addition, changes in muscle fibre distribution may be the cause of a retarded rate of force development; Van Loon et al. (2004) reported a non-significant reduction of the area occupied by type II muscle fibres compared to that of type I muscle fibres in people with diabetes. Based on the present study different explanations for the prolonged muscle activation cannot be ruled out. For future studies it might be challenging to evaluated changes in the excitation-contraction coupling in diabetic muscles.

\subsection{Gait velocity}

As reported in numerous, previous studies, changing walking velocity considerably influenced spatiotemporal gait characteristics and joint kinematics. The effects found in the present study resemble the trends reported in studies that systematically manipulated gait velocities (Lelas et al., 2003; Stoquart et al., 2008) and those of diabetic studies in which velocity was unintentionally changed; shorter stride duration, larger stride length and more prominent joint angle amplitudes when velocity was increased.

The imposed velocity was for all participants an artificial condition. It is reasonable to assume that the larger the difference between the preferred and the imposed velocity, the more the individual's effort needed to adapt to the imposed velocity. So in general, for DPN and DC participants the imposed velocity would have been less natural than for HC subjects. This might be a confounding factor introduced by the imposed velocity condition. Although spatiotemporal characteristics were found to be similar between groups in the imposed velocity, it cannot be excluded that the different adaptation effort required may have contributed to some of the differences found in joint kinematics and muscle activation patterns between the groups.

\section{Conclusion}

In this study the influences of slower gait velocity in people with diabetes and of diabetes itself on spatiotemporal gait characteristic, joint angle patterns and timing of muscle activation were determined. It can be concluded that differences in spatiotemporal gait characteristics origin from the lower gait velocity that people with diabetes prefer. Adaptations in joint angles and timing of muscle activation occurred to be the mixed effect of diabetes and the lower preferred gait velocity. Diabetes and diabetic polyneuropathy were found to result in a prolonged activity of muscles involved in braking the forward velocity after heel strike. We speculate that a slower rate of force development underlies this adapted timing; either caused by disturbed neural activation, hampered excitation-contraction coupling within muscles or changed fibre type distribution. Future studies will have to point out which disturbances underlie the adapted activation patterns in diabetes.

\section{Acknowledgements}

The participation of Ellen Sesink, Martine Bakker and Marloes van Riemsdijk in the recruitment of subjects and the process of data-acquisition is highly acknowledged.

\section{Appendix A. Supplementary material}

Supplementary data associated with this article can be found, in the online version, at doi:10.1016/j.clinbiomech.2010.02.005.

\section{References}

Abboud, R.J., Rowley, D.I., Newton, R.W., 2000. Lower limb muscle dysfunction may contribute to foot ulceration in diabetic patients. Clin. Biomech. 15, 37-45.

Akashi, P.M.H., Sacco, I.C.N., Watari, R., Hennig, E., 2008. The effect of diabetic neuropathy and previous foot ulceration in EMG and ground reaction forces during gait. Clin. Biomech. 23, 584-592.

Allet, L., Armand, S., Golay, A., Monnin, D., Bie, R.A.D., Bruin, E.D.D., 2008. Gait characteristics of diabetic patients: a systematic review. Diabetes Metab. Res. Rev. 24, 173-191. 
Cameron, N.E., Cotter, M.A., Robertson, S., 1990. Changes in skeletal muscle contractile properties in streptozocin-induced diabetic rats and role of polyol pathways and hypoinsulinemia. Diabetes 3, 460-465.

Caselli, A., Pham, H., Giurini, J.M., Armstrong, D.G., Veves, A., 2002. The forefoot-torearfoot plantar pressure ratio is increased in severe diabetic neuropathy and can predict foot ulceration. Diabetes Care 25, 1066-1071.

Cavanagh, P.R., Derr, J.A., Ulbrecht, J.S., Maser, R.E., Orchard, T.J., 1992. Problems with gait and posture in neuropathic patients with insulin-dependent diabetes mellitus. Diabet. Med. 9, 469-474.

Cavanagh, P.R., Simoneau, G.G., Ulbrecht, J.S., 1993. Ulceration, unsteadiness, and uncertainty: the biomechanical consequences of diabetes mellitus. J. Biomech. 26 (Suppl 1), 23-40.

Courtemanche, R., Teasdale, N., Boucher, P., Fleury, M., Lajoie, Y., Bard, C., 1996. Gait problems in diabetic neuropathic patients. Arch. Phys. Med. Rehabil. 77, 849855.

Giacomozzi, C., Caselli, A., Macellari, V., Giurato, L., Lardieri, L., Uccioli, L., 2002. Walking strategy in diabetic patients with peripheral neuropathy. Diabetes Care 25, 1451-1457.

Gregg, E.W., Beckles, G.L., Williamson, D.F., Leveille, S.G., Langlois, J.A., Engelgau, M.M., Narayan, K.M., 2000. Diabetes and physical disability among older US adults. Diabetes Care 23, 1272-1277.

Gutierrez, E.M., Helber, M.D., Dealva, D., Ashton-Miller, J.A., Richardson, J.K., 2001. Mild diabetic neuropathy affects ankle motor function. Clin. Biomech. 16, 522528.

Hermens, H.J., Freriks, B., Disselhorst-Klug, C., Rau, G., 2000. Development of recommendations for SEMG sensors and sensor placement procedures. J. Electromyogr. Kinesiol. 10, 361-374.

Hof, A.L., 1996. Scaling gait data to body size. Gait Posture 4, 222-223.

Hortobágyi, T., Solnik, S., Gruber, A., Rider, P., Steinweg, K., Helseth, J., Devita, P. 2009. Interaction between age and gait velocity in the amplitude and timing of antagonist muscle coactivation. Gait Posture 29, 558-564.

Hug, F., Dorel, S., 2009. Electromyographic analysis of pedaling: a review. J. Electromyogr. Kinesiol. 19, 182-198.

Katoulis, E.C., Ebdon-Parry, M., Lanshammar, H., Vileikyte, L., Kulkarni, J., Boulton, A.J., 1997. Gait abnormalities in diabetic neuropathy. Diabetes Care 20, 19041907.

Kwon, O.-Y., Minor, S.D., Maluf, K.S., Mueller, M.J., 2003. Comparison of muscle activity during walking in subjects with and without diabetic neuropathy. Gait Posture 18, 105-113.

Lavery, L.A., Armstrong, D.G., Wunderlich, R.P., Tredwell, J., Boulton, A.J.M., 2003. Predictive value of foot pressure assessment as part of a population-based diabetes disease management program. Diabetes Care 26, 1069-1073.

Lelas, J.L., Merriman, G.J., Riley, P.O., Kerrigan, D.C., 2003. Predicting peak kinematic and kinetic parameters from gait speed. Gait Posture 17, 106-112.
Meier, M.R., Desrosiers, J., Bourassa, P., Blaszczyk, J., 2001. Effect of Type II diabetic peripheral neuropathy on gait termination in the elderly. Diabetologia 44,585 592

Menz, H.B., Lord, S.R., St George, R., Fitzpatrick, R.C., 2004. Walking stability and sensorimotor function in older people with diabetic peripheral neuropathy. Arch. Phys. Med. Rehabil. 85, 245-252.

Mueller, M.J., Minor, S.D., Sahrmann, S.A., Schaaf, J.A., Strube, M.J., 1994. Differences in the gait characteristics of patients with diabetes and peripheral neuropathy compared with age-matched controls. Phys. Ther. 74 (299-308), 309-313 (discussion).

Nielsen, J.F., Andersen, H., Sinkjær, T., 2004. Decreased stiffness at the ankle joint in patients with long-term Type 1 diabetes. Diabet. Med. 21, 539-544.

Pataky, Z., Assal, J.P., Conne, P., Vuagnat, H., Golay, A., 2005. Plantar pressure distribution in type 2 diabetic patients without peripheral neuropathy and peripheral vascular disease. Diabetic Med. 22, 762-767.

Petrofsky, J., Lee, S., Bweir, S., 2005. Gait characteristics in people with type 2 diabetes mellitus. Eur. J. Appl. Physiol. 93, 640-647.

Richardson, J., Ching, C., Hurvitz, E., 1992. The relationship between electromyographically documented peripheral neuropathy and falls. J. Am. Ger. Soc. 40, 1008-1012.

Sacco, I.C., Amadio, A.C., 2003. Influence of the diabetic neuropathy on the behavior of electromyographic and sensorial responses in treadmill gait. Clin. Biomech. (Bristol, Avon) 18, 426-434.

Savelberg, H.H.C.M., Schaper, N.C., Willems, P.J.B., De Lange, A.L.H., Meijer, K., 2009. Redistribution of joint moments is associated with changed plantar pressure in diabetic polyneuropathy. BMC Musculoskelet. Disord. 10, 16.

Stoquart, G., Detrembleur, C., Lejeune, T., 2008. Effect of speed on kinematic, kinetic, electromyographic and energetic reference values during treadmill walking. Clin. Neurophysiol. 38, 105-116.

Valk, G.D., Nauta, J.J.P., Strijers, R.L.M., Bertelsman, F.W., 1992. Clinical examination versus neurophysiological examination in the diagnosis of polyneuropathy. Diabet. Med. 9, 716-721.

Van Deursen, R.W.M., Sanchez, M.M., Derr, J.A., Becker, M.B., Ulbrecht, J.S. Cavanagh, P.R., 2001. Vibration perception threshold testing in patients with diabetic neuropathy: ceiling effects and reliability. Diabet. Med. 18, 46-475.

Van Loon, L.J.C., Koopman, R., Manders, R., Van Der Weegen, W., Van Kranenburg, G.P., Keizer, H.A., 2004. Intramyocellular lipid content in type 2 diabetes patients compared with overweight sedentary men and highly trained endurance athletes. Am. J. Physiol. Endocrinol. Metab. 287, E558-E565.

Yavuzer, G., Yetkin, I., Toruner, F.B., Koca, N., Bolukbas, N., 2006. Gait deviations of patients with diabetic mellitus: looking beyond peripheral neuropathy. Eur. Medicophys. 42, 127-133. 